\title{
OPEN Ultrathin polymeric films for interfacial passivation in wide band-gap perovskite solar cells
}

\begin{abstract}
Parnian Ferdowsi ${ }^{1}$, Efrain Ochoa-Martinez ${ }^{1}$, Sandy Sanchez Alonso ${ }^{2}$, Ullrich Steiner ${ }^{1}$ \& Michael Saliba ${ }^{3,4} \bowtie$

Wide band-gap perovskite solar cells have the potential for a relatively high output voltage and resilience in a degradation-inducing environment. Investigating the reasons why high voltages with adequate output power have not been realized yet is an underexplored part in perovskite research although it is of paramount interest for multijunction solar cells. One reason is interfacial carrier recombination that leads to reduced carrier lifetimes and voltage loss. To further improve the $\mathrm{V}_{\mathrm{oc}}$ of methylammonium lead tri-bromide $\left(\mathrm{MAPbBr}_{3}\right)$, that has a band-gap of $2.3 \mathrm{eV}$, interface passivation technique is an important strategy. Here we demonstrate two ultrathin passivation layers consisting of PCBM and PMMA, that can effectively passivate defects at the $\mathrm{TiO}_{2} /$ perovskite and perovskite/ spiro-OMeTAD interfaces, respectively. In addition, perovskite crystallization was investigated with the established anti-solvent method and the novel flash infrared annealing (FIRA) with and without passivation layers. These modifications significantly suppress interfacial recombination providing a pathway for improved $\mathrm{V}_{\text {oc }}$ 's from 1.27 to $1.41 \mathrm{~V}$ using anti solvent and from 1.12 to $1.36 \mathrm{~V}$ using FIRA. Furthermore, we obtained more stable devices through passivation after $140 \mathrm{~h}$ where the device retained $70 \%$ of the initial performance value.
\end{abstract}

Organic-inorganic lead halide perovskite solar cells (PSCs) have attracted enormous interest in the past few years due to their ease of fabrication, low cost and performances rivaling the best thin-film photovoltaic devices ${ }^{1-5}$. The power conversion efficiency (PCE) of PSCs has leapt from $3.8 \%{ }^{6}$ in 2009 to the current world record of $25.2 \%{ }^{7}$ through improvements and engineering of solvents, interfaces and materials ${ }^{8-11}$. The perovskite material has an $\mathrm{ABX} X_{3}$ formula that is comprised of an organic/inorganic monovalent cation, $\mathrm{A}\left(\mathrm{Cs}^{+}\right.$, methylammonium $\left(\mathrm{MA}^{+}\right)$, or formamidinium $\left.\left(\mathrm{FA}^{+}\right)\right)$; a divalent metal, $\mathrm{B}\left(\mathrm{Pb}^{2+}\right)$; and a halide anion, $X\left(\mathrm{Cl}^{-}, \mathrm{Br}^{-} \text {, or } \mathrm{I}^{-}\right)^{5}$.

To date, the classic prototype perovskite methylammonium lead triiodide $\left(\mathrm{MAPbI}_{3}\right)$ has been one main focus in research due to its suitable band-gap for photovoltaics, near complete light absorption in thin films $(<1 \mu \mathrm{m})$ and its fast charge extraction rate. However, poor stability of $\mathrm{MAPbI}_{3}$, rapid degradation in humidity and nonworld-record PCEs, despite numerous optimization efforts, hamper commercialization ${ }^{1-3,12-15}$.

Methylammonium lead tribromide $\left(\mathrm{MAPbBr}_{3}\right)$ with a large band-gap of $2.3 \mathrm{eV}$, thus permitting a $V_{\mathrm{OC}}$ of nearly $2.0 \mathrm{~V}$, can be a promising optoelectronic alternative to $\mathrm{MAPbI}_{3}(1.5 \mathrm{eV})$ due to its good charge transport and higher stability against air and moisture ${ }^{3,16}$.

$\mathrm{MAPbBr}_{3}-\mathrm{PSCs}$ received however less attention due to their high band-gaps that are unsuited for high-performance solar cells. For example, $\mathrm{MAPbI}_{3}$-PSCs have been reported with short circuit currents $\left(J_{\mathrm{SC}}\right)$ of $20.5 \mathrm{~mA} /$ $\mathrm{cm}^{2}$ and open-circuit voltages $\left(V_{\mathrm{OC}}\right)$ of $1.26 \mathrm{~V}^{17}$, while, $\mathrm{MAPbBr}$ devices with $J_{\mathrm{SC}}=4.8 \mathrm{~mA} / \mathrm{cm}^{2}$ and $V_{\mathrm{OC}}=1.37 \mathrm{~V}$ have been shown ${ }^{18}$. It is noteworthy that $\mathrm{MAPbI}_{3}$ devices have achieved high voltages compared to the narrow band-gap of the material. On the other hand, $\mathrm{MAPbBr}_{3}$ devices exhibited a $V_{\mathrm{OC}}$ of only $1.37 \mathrm{~V}$ compared to its wide band-gap of $2.3 \mathrm{eV}$. There is therefore still much potential to investigate the improvement of the open-circuit voltage for wide band-gap PSCs. It is noteworthy that higher $V_{\mathrm{OC}}$ f for $\operatorname{MAPbBr}_{3}\left(1.47 \mathrm{~V}^{19}, 1.58^{20}\right.$ and $\left.1.61^{21}\right)$ have been reported but these data is related to the structures which are different with our structure engineering. For instance, Noel et al. used the $\mathrm{n}-\mathrm{i}-\mathrm{p}$ device architecture with single-walled carbon nanotubes (SWCNTs) interpenetrated with spiro-OMeTAD as the hole extraction layer $\left(\mathrm{FTO} / \mathrm{SnO}_{2} / \mathrm{CH}_{3} \mathrm{NH}_{3} \mathrm{PbBr}_{3} / \mathrm{SWCNT} /\right.$ spiro$\mathrm{OMeTAD} / \mathrm{Au}$ ) and they prepared the perovskite solution using acetonitrile/methylamine solvent system ${ }^{19}$. Wu

\footnotetext{
${ }^{1}$ Adolphe Merkle Institute, University of Fribourg, 1700 Fribourg, Switzerland. ${ }^{2}$ Laboratory of Photomolecular Science (LSPM), École Polytechnique Fédéral de Lausanne (EPFL), Station 6, 1015 Lausanne, Switzerland. ${ }^{3}$ Institute for Photovoltaics (ipv), University of Stuttgart, Pfaffenwaldring 47, 70569 Stuttgart, Germany. ${ }^{4}$ Helmholtz Young Investigator Group FRONTRUNNER, IEK5-Photovoltaik, Forschungszentrum Jülich, 52425 Jülich, Germany. ${ }^{\varpi}$ email: michael.saliba@ipv.uni-stuttgart.de
} 
et al. reported an inverted $\mathrm{CH}_{3} \mathrm{NH}_{3} \mathrm{PbBr}_{3}$ cell using Indene-C60 Bisadduct (ICBA) as an acceptor and they showed the importance of energy level matching of electron transport layer using ICBA ${ }^{21}$.

Furthermore, higher performance device based on $\mathrm{MAPbBr}_{3}\left(1.45 \mathrm{~V}, 9.75 \mathrm{~mA} / \mathrm{cm}^{2}, 8.7 \% \mathrm{PCE}\right)$ has been reported by Sheng et al., but they synthesized $\mathrm{CH}_{3} \mathrm{NH}_{3} \mathrm{Br}$ and then used a vapor-assisted method for depositing and fully crystalizing $\mathrm{MAPbBr}_{3}$ film on mesoporous $\mathrm{TiO}_{2}{ }^{22}$. In addition, Subhani et al. showed high performance for $\mathrm{MAPbBr}_{3}$ PSCs $\left(1.40 \mathrm{~V}, 8.93 \mathrm{~mA} / \mathrm{cm}^{2}, 9.54 \% \mathrm{PCE}\right)$ utilizing diphenylether (DPE) as an anti-solvent ${ }^{23}$. Regarding device designing, there is a similar device design with our work that has been reported for different perovskite $\left(\mathrm{Cs}_{0.07} \mathrm{Rb}_{0.03} \mathrm{FA}_{0.765} \mathrm{MA}_{0.135} \mathrm{PbI}_{2.55} \mathrm{Br}_{0.45}\right)$ by Peng et al. ${ }^{24}$. Our work is on $\mathrm{MAPbBr}$, with different energy level, and yet the same method works.

If realized, high open-circuit voltages offer considerable opportunities for different applications such as water splitting, light-emitting devices, detectors and the pathway to an all-perovskite multijunction device that requires wide band-gap perovskites with high $V_{\mathrm{OC}}{ } \mathrm{s}^{1,3,25}$. Therefore, realizing a high band-gap perovskite material has been a neglected research area and future progress will depend on analyzing and closing the voltage gap in wide band-gap perovskites.

One reason for $V_{\mathrm{OC}}$ values that lie much below the band-gap of the material is recombination at the device interfaces, leading to reduced carrier lifetimes with consequent voltage loss. There are three main approaches to address this issue and to improve the $V_{\mathrm{OC}}$ of $\mathrm{MAPbBr}_{3}$ PSCs, such as reducing the defect density by adding dopants $^{5,26}$, using alternative transport layers ${ }^{27,28}$, and interface passivation techniques that reduce the recombination at the perovskite/transport layer interfaces ${ }^{4,29-31}$.

One recent example for interface passivation are polymeric layers that reduce the surface roughness, recombination at the interface and improve stability by blocking metal electrode migration into the perovskite layer at elevated temperatures. This strategy is used for both the interface of electron-transporting layer (ETL)/perovskite and the hole-transporting layer (HTL)/perovskite. For example, it has been shown that the addition of a solution-processed PMMA (Poly(methyl methacrylate)) layer at perovskite/HTL interface improves the photovoltaic performance and stability ${ }^{29}$. Also, it was demonstrated that an ultrathin passivation layer consisting of a PMMA:PCBM ([6,6]-phenyl- $\mathrm{C}_{61}$-butyric acid methyl ester) mixture can benefit the perovskite/ $\mathrm{TiO}_{2}$ interface through passivating the defects and suppressing interfacial recombination ${ }^{4}$.

Here, we demonstrate ultrathin passivation layers consisting of PMMA, PCBM and a PMMA/PCBM mixture that can effectively passivate defects at the perovskite/ ETL and perovskite/HTL interfaces, respectively. These modifications significantly suppress interfacial recombination, providing a pathway for improved $V_{\mathrm{OC}}$ 's.

In addition, crystallization and film-formation are important key components in high quality perovskite materials. In this context, we have experimentally investigated the perovskite crystallization with the established anti-solvent and the "novel flash infrared annealing (FIRA)"32,33 methods, with and without passivation layers. This is the first demonstration of FIRA for $\mathrm{MAPbBr}_{3}$, revealing an altered film morphology and therefore a novel strategy to control the crystallization process. Additionally, interesting approaches have been investigated by using high-intensity near-infrared radiation technique to rapidly anneal perovskite layers ${ }^{34-36}$. Troughton et al., proposed a new method of post annealing perovskite films within a short period of time, i.e. under $2.5 \mathrm{~s}$ using near-infrared radiation ${ }^{34}$. In another work ${ }^{35}$, Baker et al., reduced the heating time of the mesoporous layers from two hours to $30 \mathrm{~s}$. Lately, Martin et al., reported fabrication of flexible perovskite solar cells through rapid thermal annealing technique to reduce post-deposition time from 150 to $14 \mathrm{~s}^{36}$.

Given the advantages of using the FIRA method for the manufacture of photovoltaic devices, such as environmentally and rapid processing ${ }^{37,38}$, combining the use of polymeric passivation and the FIRA method is a step forward to improve the efficiency and stability of the wide-band-gap PSCs. However, to the best of our knowledge, the combination of the passivation technique of the $\mathrm{mp}-\mathrm{TiO}_{2} /$ perovskite interface and the use of a rapid infrared annealing process to crystallize the precursor has not been investigated so far.

\section{Results}

Device characterization. Methylammonium lead bromide perovskite $\left(\mathrm{MAPbBr}_{3}\right)$ was fabricated on mesoporous $\mathrm{TiO}_{2}$ layers by the anti-solvent and FIRA method. Figure 1a,b show the device architecture of a PSC and fabricated device with thin PCBM and PMMA layers on top of the mesoporous $\mathrm{TiO}_{2}$ and the perovskite layer, respectively.

Cross-sectional SEM images of anti-solvent and FIRA devices are shown in Fig. 1c,d. Top view SEM images of a PSC, using FIRA, are presented in the Supporting Information (SI) in Fig. S1.

Figure 1c reveals that the typical thicknesses of the compact $\mathrm{TiO}_{2}$, mesoporous $\mathrm{TiO}_{2}, \mathrm{MAPbBr}_{3}$, spiroOMeTAD and gold layers were approximately 67, 100, 336, 137 and $80 \mathrm{~nm}$, respectively. For the FIRA device in Fig. 1d, the compact and mesoporous $\mathrm{TiO}_{2}$ layer (combined), perovskite and spiro thickness were about 185, 330 and $120 \mathrm{~nm}$, respectively, and those of the PCBM and PMMA were $12 \mathrm{~nm} \pm 3$ and $1.5 \mathrm{~nm} \pm 1$ according to AFM measurements (Fig. S2). The results indicate that the PMMA layer is sufficiently thin to permit the tunneling of charge carriers to the electrodes. They are sufficiently thick to fill conformally cover the interfaces and they may passivate the defects the perovskite top surface.

To evaluate the passivation performance of the ultrathin polymeric layer at the interface of perovskite and $\mathrm{HTL}$, we prepared cells with and without thin PMMA $(0.1 \mathrm{mg} / \mathrm{ml})$ films at the $\mathrm{MAPbBr}_{3} / \mathrm{HTL}$ interface through the anti-solvent method and compare the device performances of these cells. The $V_{\mathrm{OC}}$ and PCE of the solar cells improved from $1.31 \pm 0.07$ to $1.34 \pm 0.04 \mathrm{~V}$ on average by the addition of a thin PMMA layer (Supporting Information, Fig. S3).

Furthermore, to evaluate the effect of a second passivation layer at the ETL/perovskite interface, we prepared cells with different PMMA:PCBM ratios (w/w): a control cell (no passivation layer), 1:3, 1:5 and 1:10. The obtained data showed no clear trend (Fig. S4). We then prepared cells with pure PMMA (1 mg/ml), pure PCBM 


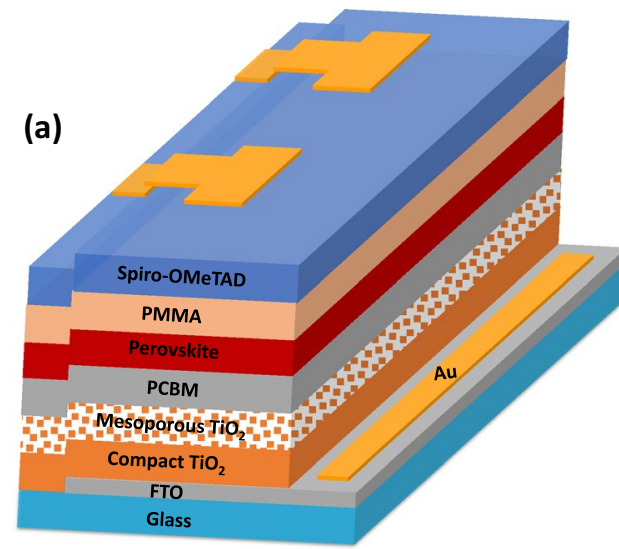

(c)

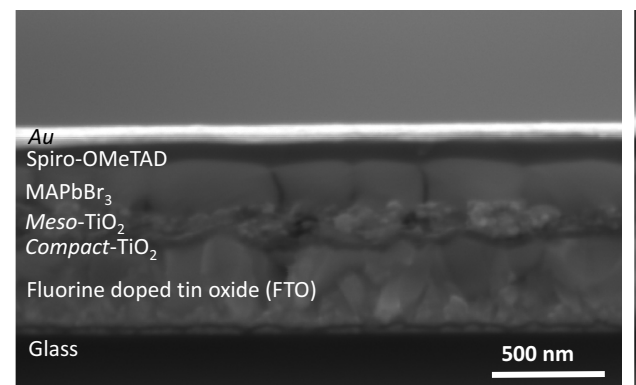

(b)

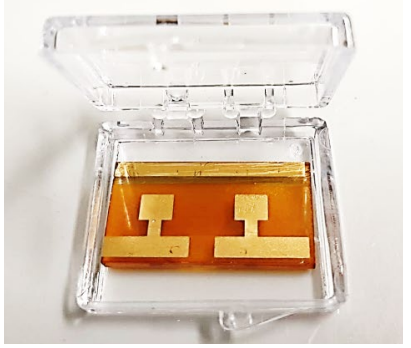

(d)

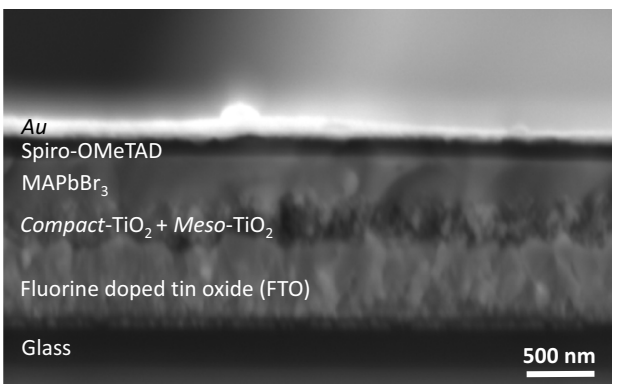

Figure 1. (a) Schematic of the device structure, (b) Fabricated device $\left(\mathrm{MAPbBr}_{3}\right),(\mathbf{c}) \mathrm{SEM}$ cross-section of a perovskite solar cell; the $\mathrm{MAPbBr}_{3}$ layer was deposited by the anti-solvent technique, and (d) a FIRA-annealed

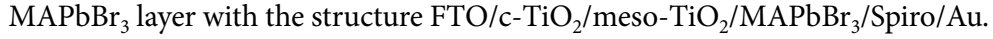

(5 mg/ml) and 1:20 (PMMA:PCBM) films at the ETL/perovskite interface in addition of PMMA $(0.1 \mathrm{mg} / \mathrm{ml})$ on top of the perovskite. All other cell fabrication steps were kept the same. The results showed that pure PCBM at the bottom of $\mathrm{MAPbBr}_{3}$ in addition of pure PMMA on top, improved the $V_{\mathrm{OC}}$ significantly from $1.25 \pm 0.04$ to $1.39 \pm 0.01 \mathrm{~V}$, on average, as well as the PCE from $4.9 \pm 0.33$ to $6.1 \pm 0.40 \%$ compared to the devices with one passivation layer (Fig. S5).

Figure 2 shows the device statistics (short circuit current, open circuit voltage, fill factor (FF) and PCE) of the control devices (no passivation) and passivated devices (P + PMMA, PCBM + P + PMMA, where P denotes the perovskite layer) collected for different batches using the anti-solvent (a) and FIRA (b) methods. We note improvements in all device parameters through passivation (Fig. 2a) and observe that two ultrathin layers at the top and bottom of perovskite have the most positive effect on the performance $(5.74 \pm 0.59 \%)$ compared to the devices with only one passivation layer $(4.67 \pm 0.45 \%)$ and no passivation layer $(3.85 \pm 0.66 \%)$. In addition, the voltage improvement for FIRA devices through passivation is shown in Fig. 2b. It is important to mention that FIRA devices required a separate optimization in the IR annealing time at $1.4 \mathrm{~s}$ and a solvent ratio of 3:1 for DMF:DMSO (Figs. S6 and S7).

To further characterize the passivation performance of the intermediate layers, we also investigated the photo-

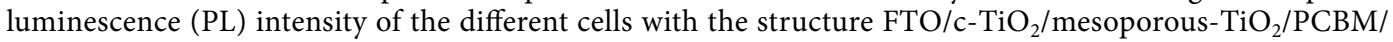
$\mathrm{MAPbBr} r_{3} / \mathrm{PMMA}$ and $\mathrm{FTO} / \mathrm{c}-\mathrm{TiO}_{2} /$ mesoporous- $\mathrm{TiO}_{2} / \mathrm{MAPbBr}_{3}$. We present the UV-vis and PL data comparing devices with anti-solvent processed (solid line) and FIRA annealed (dashed line) $\mathrm{MAPbBr}_{3}$ layers in Fig. 3.

As previously reported ${ }^{4}$, the devices with the highest $V_{\mathrm{OC}}$ have the highest PL intensity. As shown in Fig. 2, devices with two passivation layers result in a considerable $V_{\mathrm{OC}}$ improvement. This agrees with the PL data for devices that were prepared with both the anti-solvent and FIRA method. The PL intensity of passivated devices is higher than that of the non-passivated ones (Fig. 3a).

Therefore, we conclude that the increase in PL intensity for our best passivated cells suggests that the surface recombination at the ETL/perovskite and perovskite/HTL interfaces is significantly suppressed by the addition of the thin intermediate layers, resulting in an increased $V_{\mathrm{OC}}$. The PL spectra shows peaks positioned at 545 and $542 \mathrm{~nm}$ for passivated devices by anti-solvent and FIRA, respectively, and at 544 and 546 for non-passivated ones, respectively.

The absorption spectra of cells is shown in Fig. 3b. Devices prepared through the anti-solvent method exhibited local absorption maxima of $524 \mathrm{~nm}$ and FIRA-annealed devices had maximum absorption peaks positioned at $522 \mathrm{~nm}$. As shown in Fig. 3b, passivated cells have higher absorption compared to non-passivated ones which agrees with the PL data.

Furthermore, in Figs. 4 and 5 we investigated long-term device stability of the devices in a nitrogen atmosphere held at room temperature under constant illumination of one sun. A $J V$ scan was taken periodically to extract the observed device parameters. Figures 4 and 5 shows the variation of the normalized output power, 
(a)

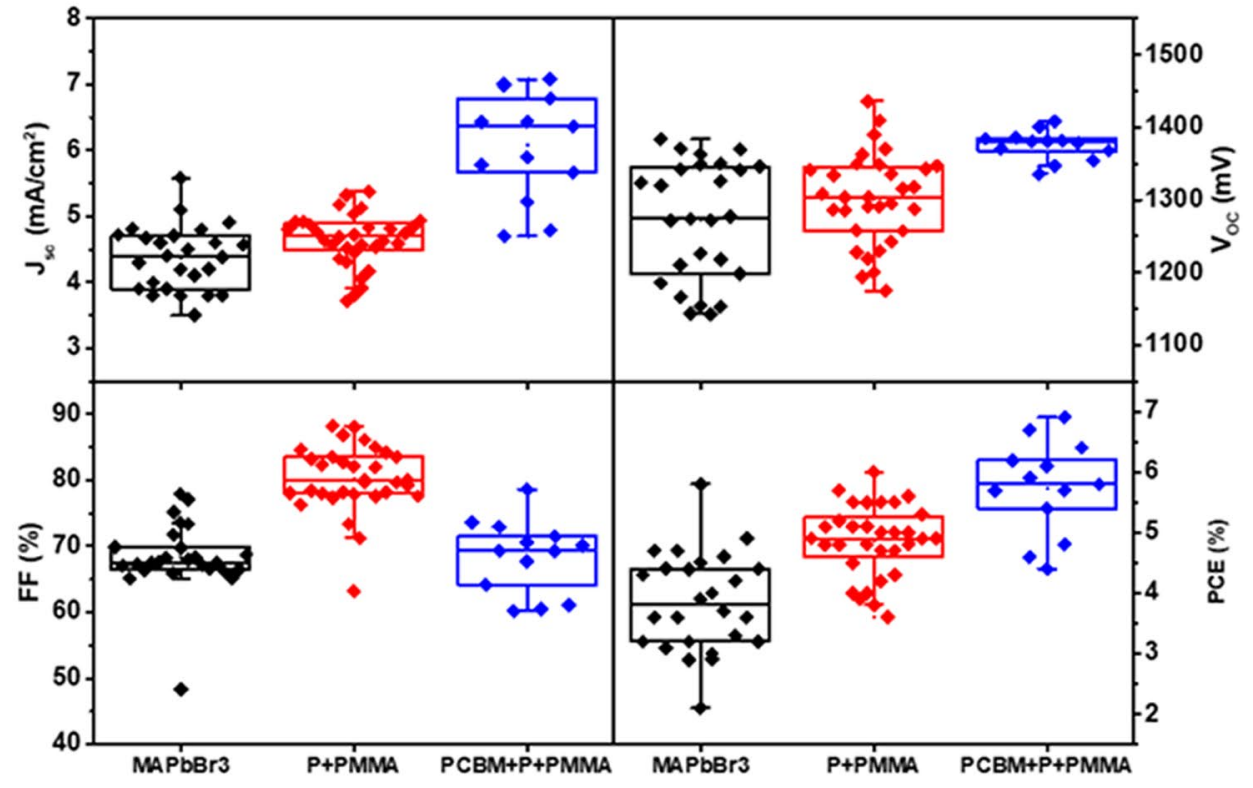

(b)

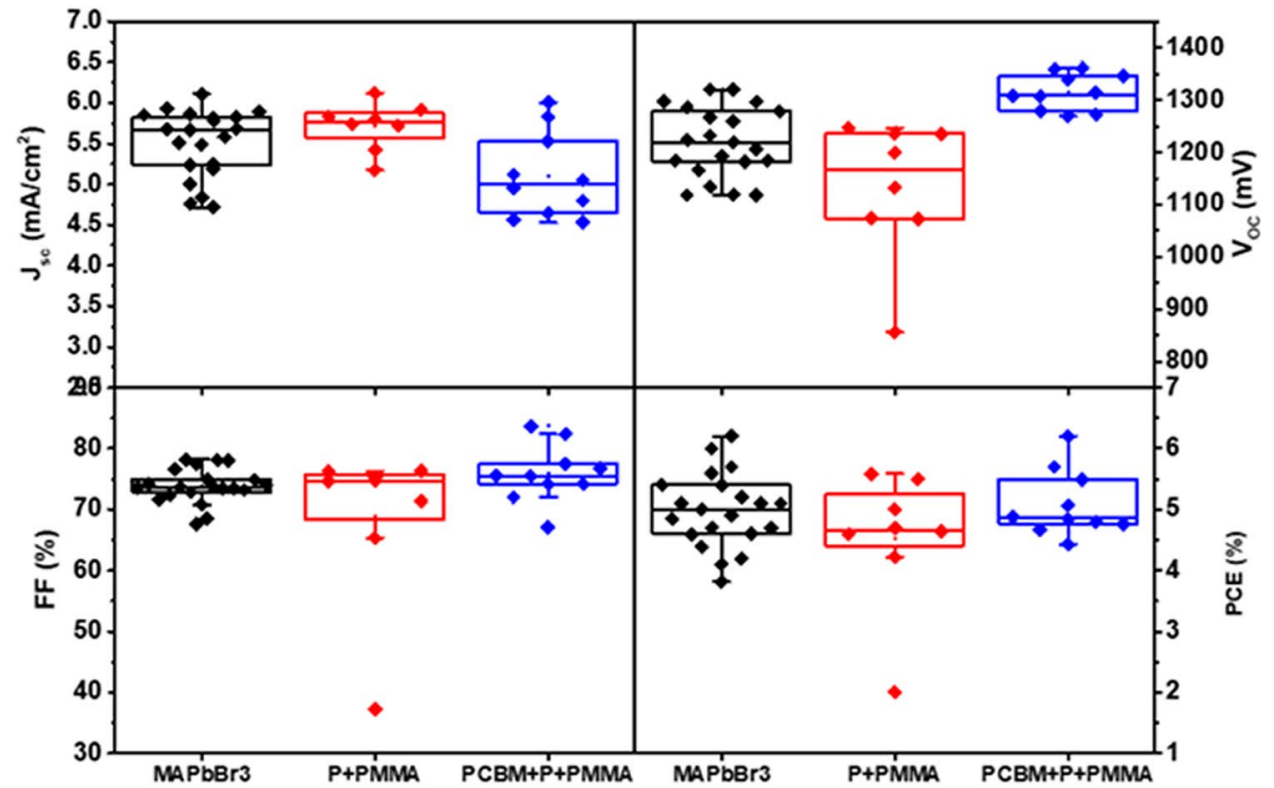

Figure 2. Statistical distribution of the photovoltaic parameters for cells with/without PMMA and PCBM passivation layers: (a) anti-solvent deposited $\mathrm{MAPbBr}_{3}$ layers, (b) FIRA-annealed $\mathrm{MAPbBr}_{3}$ layers.

short-circuit photocurrent, open circuit voltage and fill factor of three devices using no passivation, one and two passivation layers, comparing anti-solvent and FIRA-annealed devices, respectively.

Figure 4a shows that without passivation layers, the loss in cell performance is significant during the initial hours. In contrast, the two passivated devices showed only small losses and retained $70 \%$ of the initial performance after $140 \mathrm{~h}$ of continuous illumination. The PCE of the non-passivated device dropped quickly after $20 \mathrm{~h}$ to $83 \%$ of its initial performance, then decreased with a gentle slope from $80 \%$ at $25 \mathrm{~h}$ to around $67 \%$ at $70 \mathrm{~h}$, and then stayed relatively constant reaching $60 \%$ of the initial performance after $140 \mathrm{~h}$. The device with only one PMMA passivation layer also decreased to $60 \%$ of its initial performance after $140 \mathrm{~h}$.

The variation of $J_{\mathrm{SC}}$ exhibited a similar trend and all the devices were followed by a slow recovery during ca. $10 \mathrm{~h}$ of light soaking and the device with two passivation layers reached to $92 \%$ of its initial current (Fig. 4b). 
(a)

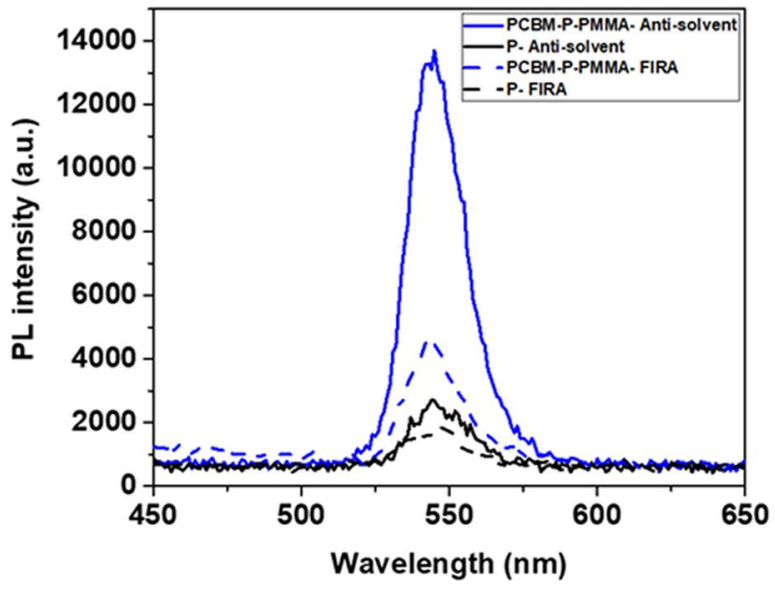

(b)

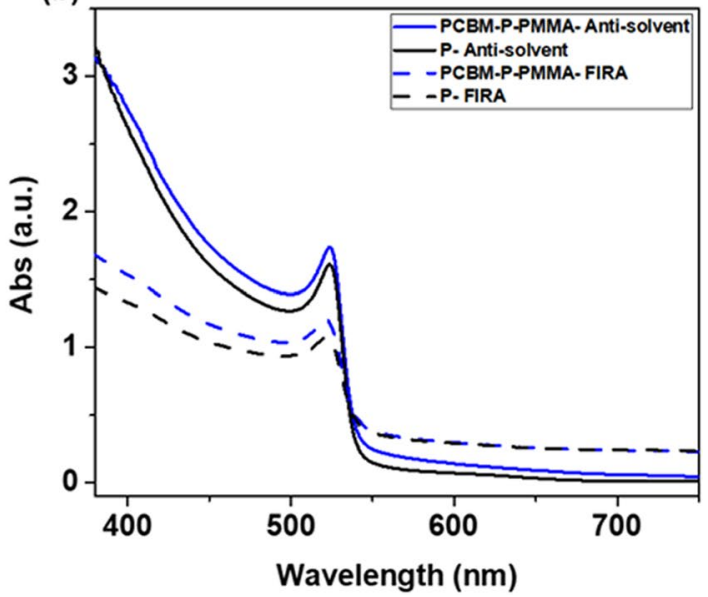

Figure 3. (a) Photoluminescence (PL) and (b) absorption spectra of cells with the structure $\mathrm{FTO} / \mathrm{c}-\mathrm{TiO}_{2} / \mathrm{meso}^{-}$ $\mathrm{TiO}_{2} / \mathrm{PCBM} / \mathrm{MAPbBr}_{3} / \mathrm{PMMA}$ and $\mathrm{FTO} / \mathrm{c}-\mathrm{TiO}_{2} /$ meso-TiO $_{2} / \mathrm{MAPbBr}_{3}$.

(a)

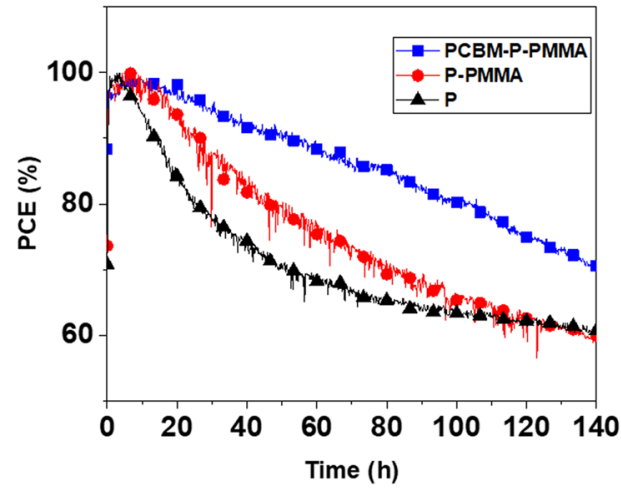

(c)

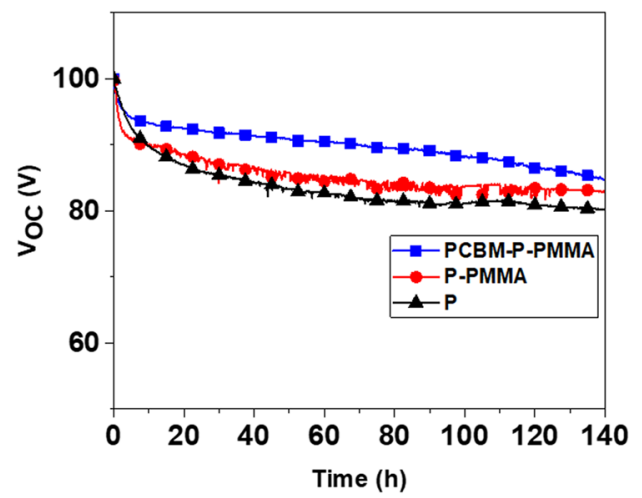

(b)

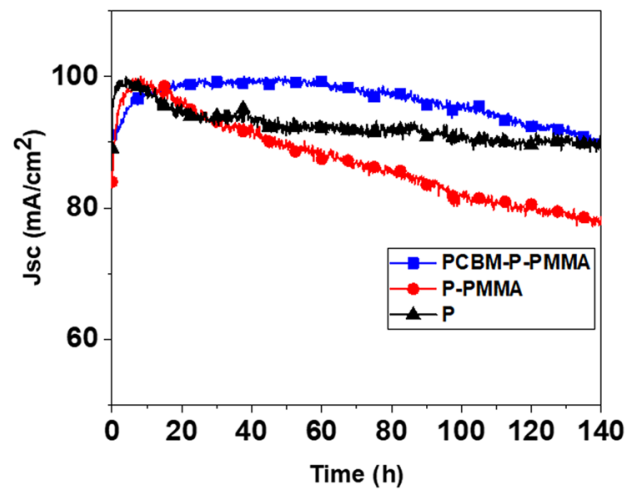

(d)

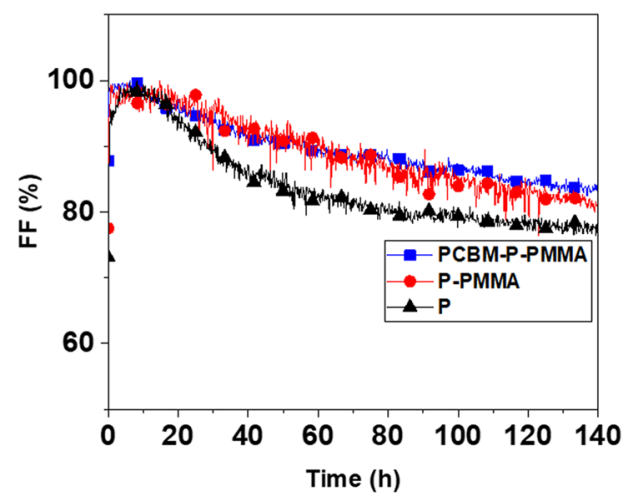

Figure 4. Variation of main normalized photovoltaic parameters (a) output power, (b) short-circuit photocurrent, (c) open circuit voltage, and (d) fill factor of anti-solvent-manufactured devices with two passivation layers (blue curve), one passivation layers (red curve) and without passivation layers (black curve) aged at room temperature after $140 \mathrm{~h}$ in a nitrogen atmosphere.

For all the devices, the $V_{\mathrm{OC}}$ remained nearly constant (Fig. 4c). It is noted that the obtained results show a further improvement in the $V_{\mathrm{OC}}$ using two passivation layers compare to the reported highest value with the same structure in literature $(1.37 \mathrm{~V})^{18}$.

Fill factor variations reveal similar trends for the output power for no, one and two passivation layers reaching 78,82 and $84 \%$ of their initial FF, respectively (Fig. 4 d).

The stability data highlights the significance of the device architecture and the important role of passivation layers at the perovskite interfaces for the long-term stability. 
(a)

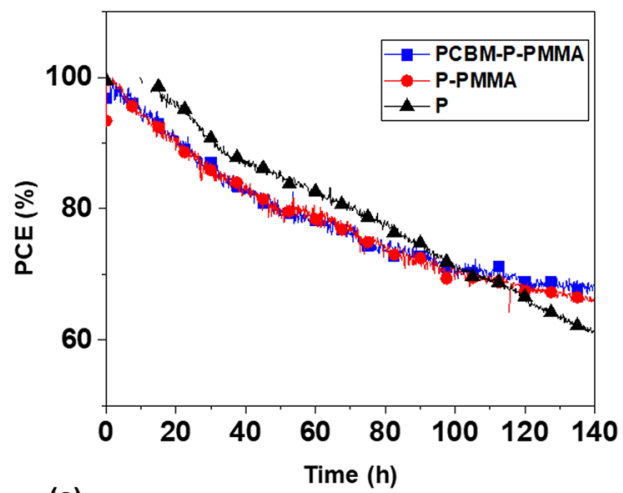

(c)

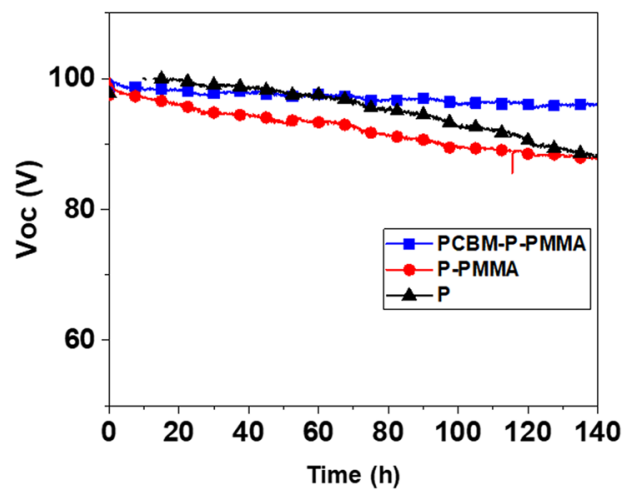

(b)

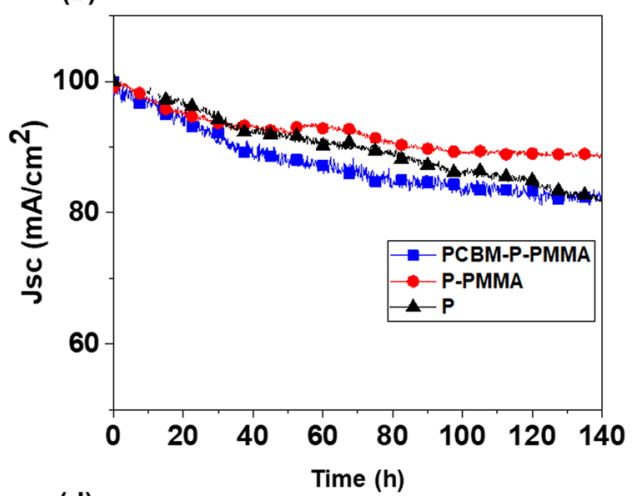

(d)

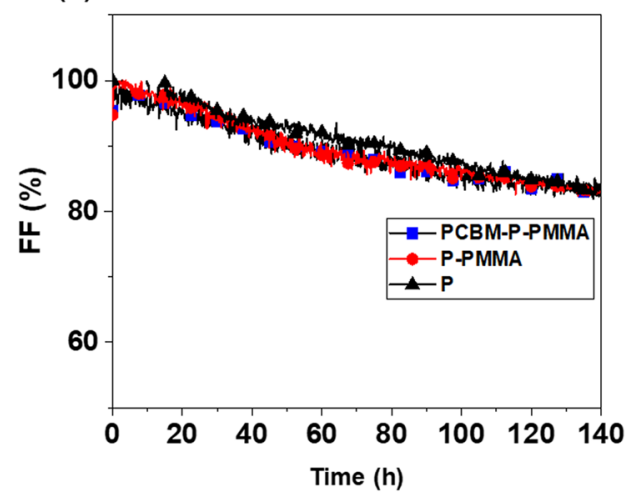

Figure 5. Variation of main normalized photovoltaic parameters (a) output power, (b) short-circuit photocurrent, (c) open circuit voltage, and (d) fill factor of FIRA-annealed $\mathrm{MAPbBr}_{3}$ devices with two passivation layers (blue curve), one passivation layers (red curve) and without passivation layers (black curve) aged at room temperature after $140 \mathrm{~h}$ in a nitrogen atmosphere.

$\mathrm{Li}$ et al. proved the passivation effect of the surface trap states on device stability ${ }^{39}$. These two-passivation layers decrease the trap density of states thus prevent unwanted trap-assisted electron-hole recombination at the interfaces and create physical barriers between transportation layers and the perovskite film. In addition to that, the PCBM passivation was deposited at the interface of $\mathrm{TiO}_{2}$ and perovskite film to physically separate ETL from perovskite layer. This leads to an improvement in the device stability by enhancing oxygen tolerance and avoiding the rapid degradation which can be caused by the UV sensitive $\mathrm{TiO}_{2}$ surface ${ }^{39,40}$. Moreover, further improvement in device stability is achieved due to the fact that PMMA can behave as a shielding layer for the perovskite film against humidity and oxygen under ambient conditions ${ }^{29}$.

In Fig. 5a, for the FIRA processed devices the PCE of the non-passivated device dropped more quickly than the other two devices and reached around $60 \%$ of the initial performance after $140 \mathrm{~h}$. The devices with one and two passivation layers showed similar trends and decreased with a gentle slope to a more than 70\% PSC decline at $95 \mathrm{~h}$, and then stayed relatively constant reaching around $70 \%$ of the initial performance after $140 \mathrm{~h}$. Notably, PSCs with passivation thin films remain more stable against the device with a non-passivated film.

The $J_{\mathrm{SC}}$ of the unpassivated device and the one with two passivation layers reached $82 \%$ of the initial current after $140 \mathrm{~h}$, while the one with one passivation layer showed a bit more stable trend and reached to $89 \%$ of the initial $J_{\text {SC }}$ after $140 \mathrm{~h}$ (Fig. 5b).

The variation of $V_{\mathrm{OC}}$ of all devices exhibited more or less similar trends until $90 \mathrm{~h}$ and then, devices with no and one passivation layer decreased with a gentle slope to nearly $90 \%$ of the initial voltage after $140 \mathrm{~h}$. The device with two passivation layers remained nearly constant and showed $97 \%$ of its initial $V_{\mathrm{OC}}$ after $140 \mathrm{~h}$ (Fig. $5 \mathrm{c}$ ).

Fill factor variations reveal similar trends for all devices and reached close to $90 \%$ at $70 \mathrm{~h}$, and then stayed relatively constant reaching $83 \%$ of their initial FF after $140 \mathrm{~h}$ (Fig. 5d).

Typical photocurrent density-voltage $(J-V)$ curves of a PSC containing no passivation layer, one passivation layer $\left(0.1 \mathrm{mg} / \mathrm{mL}\right.$ PMMA coated on $\left.\mathrm{MAPbBr}_{3}\right)$ and two passivation layers $(5 \mathrm{mg} / \mathrm{mL} \mathrm{PCBM}$ at ETL/MAPbBr 3 interface in addition of top polymeric layer) made by the anti-solvent method and by FIRA-annealing are shown in Fig. 6. The corresponding photovoltaic parameters are collected in Table 1.

Figure $6 \mathrm{a}$ shows the performance of devices that were prepared by the anti-solvent method. The control cell had a PCE of $4.5 \%, V_{\mathrm{OC}}=1.27 \mathrm{~V}, J_{\mathrm{SC}}=4.82 \mathrm{~mA} \mathrm{~cm}^{-2}$ and $\mathrm{FF}=73.5$. In contrast, the cell with the two passivation layers achieved a PCE of $6.32 \%, V_{\mathrm{OC}}=1.41 \mathrm{~V}, J_{\mathrm{SC}}=6.63 \mathrm{~mA} \mathrm{~cm}{ }^{-2}$ and $\mathrm{FF}=67.7 \%$. From the obtained data, it is clear that the $V_{\mathrm{OC}}$ has improved due to the presence of one polymeric layer and that two passivation layers have a much more positive effect. 
(a)

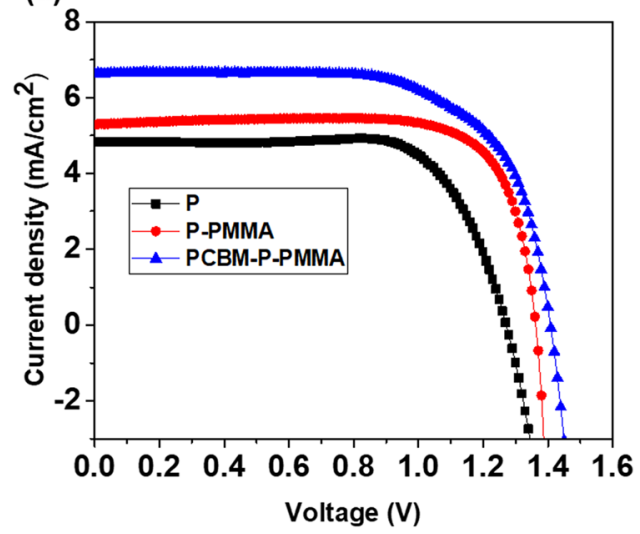

(b)

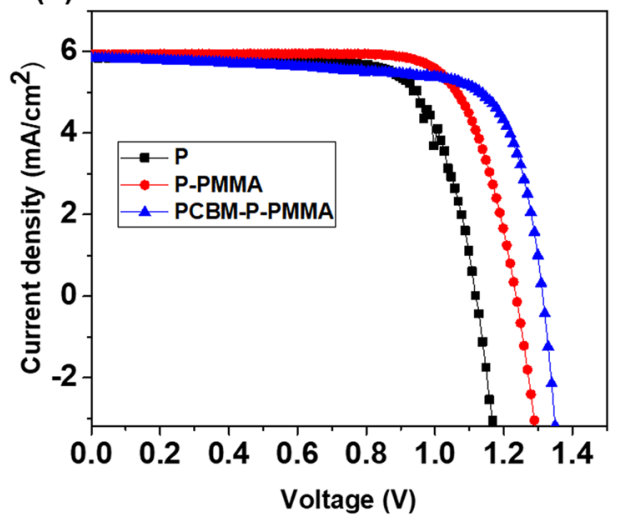

Figure 6. Current density-voltage curves of devices with and without PMMA and PCBM passivation layers, made by (a) the anti- solvent method and (b) FIRA-annealing. The scan rate was $20 \mathrm{mV} \mathrm{s}^{-1}$.

\begin{tabular}{|l|l|l|l|l|l|l|l|l|}
\hline \multirow{2}{*}{ Samples } & \multicolumn{3}{l}{$\mathbf{V}_{\text {OC }}(\mathrm{V})$} & \multicolumn{2}{l|}{$\mathrm{J}_{\text {SC }}\left(\mathbf{m A} / \mathbf{c m}^{2}\right)$} & FF & \multicolumn{2}{l|}{ PCE (\%) } \\
\cline { 2 - 10 } & Anti-solvent & FIRA & Anti-solvent & FIRA & Anti-solvent & FIRA & Anti-solvent & FIRA \\
\hline P & 1.27 & 1.12 & 4.82 & 5.85 & 73.5 & 74.1 & 4.50 & 4.85 \\
\hline P-PMMA & 1.36 & 1.24 & 5.29 & 5.92 & 78.2 & 76.3 & 5.64 & 5.58 \\
\hline PCBM-P-PMMA & 1.41 & 1.31 & 6.63 & 5.83 & 67.7 & 74.2 & 6.32 & 5.68 \\
\hline
\end{tabular}

Table 1. Photovoltaic parameters of the devices with/without passivation layers through anti-solvent and FIRA.

FIRA devices showed a similar trend and a significantly improved $V_{\mathrm{OC}}$ can be seen for this kind of device (Fig. 6b).

Therefore, ultrathin passivation layers can effectively passivate the ETL/MAPbBr3/HTL interfaces, leading to a considerable reduction in charge recombination and a dramatic increase in $V_{\mathrm{OC}}$ from 1.27 and $1.12 \mathrm{~V}$ (non-passivated) to $1.41 \mathrm{~V}$ and $1.31 \mathrm{~V}$ (two passivated) for devices manufactured by the anti-solvent method and FIRA-annealing, respectively. The passivating effects at the interfaces is an essential factor to improve the performance of perovskite solar cells. In the presence of intermediate layers, i.e. PCBM and PMMA, at the bottom and top surface of the perovskite layer, trapping effects of the photo generated electron-hole pairs are reduced. These states are typically generated by crystal defects and pinholes of the deposited perovskite layer induced by substrate roughness and grain boundaries. The PCBM and PMMA layers reduce the charge recombination rate and the forbidden energy states transitions at the interfaces by passivating interface and near-interface traps.

Furthermore, Photovoltaic parameters of champion control and passivated old devices were remeasured from both reverse and forward scans under $20 \mathrm{mV} \mathrm{s}^{-1}$ scan rate (Supporting Information (SI) in Figs. S8-S9 and Table S2).

\section{Discussion}

In this work, we show that ultrathin polymeric passivation layers consisting of PCBM and PMMA can effectively passivate the ETL/MAPbBr $3 / \mathrm{HTL}$ interfaces of wide band-gap perovskite solar cells, leading to a significant increasing in $V_{O C}$ from $1.27 \mathrm{~V}$ (non-passivated) to $1.36 \mathrm{~V}$ (one-passivation layer) and $1.41 \mathrm{~V}$ (two passivation layers) using anti solvent method. The results showed that there is a potential to further improve the $V_{\mathrm{OC}}$ and increase the electron lifetime through passivation, which was successful to reduce the interfacial charge recombination. Furthermore, this work, for the first time used FIRA technique for $\mathrm{MAPbBr}_{3}$ to control the perovskite crystallization process. We investigated the effect of passivation layers for FIRA-annealed devices and the obtained results show an $V_{\mathrm{OC}}$ improvement from $1.12 \mathrm{~V}$ (non-passivated) to $1.24 \mathrm{~V}$ (one-passivation layer) and $1.31 \mathrm{~V}$ (two passivation layers). Given the advantages of FIRA, i.e. environmentally friendly and rapid processing, this is a highly promising method for the scale-up of PSC manufacture. The long-term stability investigation show that the variation of $V_{\mathrm{OC}}$ for devices with two passivation layers remained nearly constant and reached to around $86 \%$ and $97 \%$ of their initial $V_{\mathrm{OC}}$ in devices made by the anti-solvent method and FIRA-annealing, respectively.

\section{Methods}

Substrate preparation and $\mathrm{Li}$-doping $\mathrm{TiO}_{2}$. Fluorine-doped tin oxide (FTO) pre-etched substrates (Sigma-Aldrich, TEC-7) were cleaned by sonication in $2 \%$ Hellmanex water solution, isopropyl alcohol (IPA) and ethanol, respectively. Then all the substrates were further cleaned with plasma treatment for $10 \mathrm{~min} . \mathrm{A} \mathrm{TiO}_{2}$ 
compact layer was deposited on FTO by spray pyrolysis, using oxygen as a carrier gas, at $450{ }^{\circ} \mathrm{C}$ from a precursor solution of titanium diisopropoxide bis(acetylacetonate) stock solution (75 wt.\% in isopropanol) in anhydrous ethanol. Then, a mesoporous $\mathrm{TiO}_{2}$ layer was deposited by spin coating using a $30 \mathrm{~nm}$ particle paste (Dyesol 30 NR-D) diluted in ethanol. After the spin coating, the substrates were sintered with a ramped temperature profile, keeping the temperature at $125,225,375,450$, and $25^{\circ} \mathrm{C}$ for $5,5,5$, and $30 \mathrm{~min}$, respectively, with $5,15,5$, and 5 min ramp duration between each temperature ${ }^{1,30,33}$.

Li-treatment of mesoporous $\mathrm{TiO}_{2}$ is done by spin coating a $10 \mathrm{mg} \mathrm{mL}^{-1}$ solution of Li-TFSI in acetonitrile. After cooling down, the substrates were transferred in a nitrogen atmosphere glove box to deposit the perovskite films ${ }^{41}$.

PCBM and PMMA precursor solution. For the ETL side, the PCBM precursor solution was prepared by dissolving $5 \mathrm{mg} / \mathrm{mL}$ PCBM (Sigma Aldrich, 99.5\%) in chlorobenzene.

The PCBM:PMMA $(x: 1)$ precursor solution was prepared by dissolving $x \mathrm{mg}$ PCBM and $1 \mathrm{mg}$ PMMA into $1 \mathrm{~mL}$ chlorobenzene.

The solution was spin coated statically on the substrates at $4000 \mathrm{rpm}$ for $30 \mathrm{~s}$.

For the HTL side, the PMMA precursor solution was prepared by dissolving $0.1 \mathrm{mg}$ PMMA in $1 \mathrm{~mL}$ chlorobenzene and solution was spin coated dynamically on a rotating substrate at $4000 \mathrm{rpm}$ for $30 \mathrm{~s}$.

Perovskite precursor solution and film preparation. The organic cation salts were purchased from Greatcellsolar; the lead compounds from TCI; DMF and DMSO from Sigma-Aldrich. The following formulations were composed by mixing the appropriate amounts.

Anti-solvent. The $\mathrm{MAPbBr}_{3}$ solution was prepared from a precursor solution containing $\mathrm{MABr}$ and $\mathrm{PbBr}_{2}$ $(1.5 \mathrm{M})$ in anhydrous DMF:DMSO 4:1 (v:v). (The $\mathrm{PbBr}_{2}$ solution was added to $\mathrm{MABr}$ powder; $\mathrm{PbBr}_{2}: \mathrm{MABr}$ (1:1); Final perovskite solution $(1.22 \mathrm{M})$ ).

The perovskite solution was spin coated at $3000 \mathrm{rpm}$ for $30 \mathrm{~s}$. Around $10 \mathrm{~s}$ prior to the end of the program, 100 $\mu \mathrm{L}$ of chlorobenzene was injected on the spinning substrate. Films turned yellow immediately after spin coating. The substrates were then annealed (usually at $100^{\circ} \mathrm{C}$ ) for $45 \mathrm{~min}$ in a nitrogen filled glove box.

FIRA. The $\mathrm{MAPbBr}_{3}$ solution was prepared from a precursor solution containing $\mathrm{MABr}$ and $\mathrm{PbBr}_{2}(1.4 \mathrm{M})$ in anhydrous DMF:DMSO 3:1 (v:v). (The $\mathrm{PbBr}_{2}$ solution was added to MABr powder; $\mathrm{PbBr}_{2}: \mathrm{MABr}$ (1:1); Final perovskite solution $(1.30 \mathrm{M})$ ).

The films were prepared by spin-coating of the perovskite solution in a single step at $4000 \mathrm{rpm}$ for $10 \mathrm{~s}$. in the next step, the prepared substrates were then IR irradiated for $1.4 \mathrm{~s}$ in the FIRA oven and were kept there for 20 additional seconds before removal. The hole process was done in a standard fume hood ${ }^{33}$.

Hole transporting layer and top electrode. After the perovskite annealing, the substrates were cooled down and a Spiro-OMeTAD (Lumtec) solution (70 mM in chlorobenzene) was spin coated at $4000 \mathrm{rpm}$ for $20 \mathrm{~s}$. Spiro-OMeTAD was doped with bis(trifluoromethylsulfonyl)imide lithium salt (Li-TFSI, SigmaAldrich) and 4-tert-Butylpyridine (TBP, SigmaAldrich) in the molar ratio of 0.5 and 3.3 for Li-TFSI and TBP, respectively.

Finally, gold with $80 \mathrm{~nm}$ thickness was thermally evaporated under high vacuum as top electrode ${ }^{33}$.

Characterization. All devices were tested under simulated solar irradiation $\left(100 \mathrm{~mW} / \mathrm{cm}^{2}, \mathrm{AM} 1.5 \mathrm{G}\right)$ using a solar simulator from ABET Technologies (Model Sun 2000) with a xenon arc lamp, and the solar cell response was recorded using a Metrohm PGSTAT302N Autolab. The light intensity was calibrated using a silicon reference cell from ReRa Solutions (KG5 filtered) ${ }^{33}$. Current-voltage curves were measured in a scan rate of $20 \mathrm{mV} \mathrm{s}^{-1}$ at reverse and forward bias. The cells were masked with a black metal mask $\left(0.09936 \mathrm{~cm}^{2}\right)$ to fix the active area and reduce the influence of the scattered light. UV-Vis measurements were performed on Shimadzu UV-2401PC Spectrophotometer. Scanning electron microscopy (SEM) images were obtained with a Tescan Mira3 LM FE. Photoluminescence measurements on perovskite films were performed using a Horiba Fluorolog FL 3-22 spectrometer. Atomic force microscopy (AFM) was performed on JPK NanoWizard II. Optical microscopy was done on ZEISS Axio Scope.A1.

Received: 11 November 2020; Accepted: 7 December 2020

Published online: 17 December 2020

\section{References}

1. Saliba, M. et al. Cesium-containing triple cation perovskite solar cells: improved stability\{,\} reproducibility and high efficiency. Energy Environ. Sci. 9, 1989-1997 (2016)

2. Hu, X. et al. Wide-bandgap perovskite solar cells with large open-circuit voltage of $1653 \mathrm{mV}$ through interfacial engineering. Solar $R R L$ 1800083, 1-10 (2018).

3. Lo, C. A. et al. Elucidating the methylammonium (MA) conformation in $\mathrm{MAPbBr} 3$ perovskite with application in solar cells. Inorganic Chem. 56, 14214-14219. https://doi.org/10.1021/acs.inorgchem.7b02344 (2017).

4. Peng, J. et al. Interface passivation using ultrathin polymer-fullerene films for high-efficiency perovskite solar cells with negligible hysteresis. Energy Environ. Sci. 10, 1792-1800 (2017). 
5. Saliba, M. et al. Incorporation of rubidium cations into perovskite solar cells improves photovoltaic performance. Science 354, 206-209 (2016).

6. Kojima, A., Teshima, K., Shirai, Y. \& Miyasaka, T. Organometal halide perovskites as visible-light sensitizers for photovoltaic cells. J. Am. Chem. Soc. 131, 6050-6051 (2009).

7. NREL Best Research-Cell Efficiencies. Available online: https://www.nrel.gov/pv/assets/pdfs/best-researchcell-efficiencies-19041 6.pdf (accessed on 1 April 2019).

8. Jeon, N. J. et al. Solvent engineering for high performance inorganic-organic hybrid perovskite solar cells. Nat. Mater. 13, 897-903 (2014).

9. Guerrero, A. et al. Interfacial degradation of planar lead halide perovskite solar cells. ACS Nano 10, 218-224 (2016).

10. Jeon, N. J. et al. Compositional engineering of perovskite materials for high-performance solar cells. Nature 517, 476-480 (2014).

11. Ogomi, Y. et al. $\mathrm{CH}_{3} \mathrm{NH}_{3} \mathrm{Sn}_{\mathrm{x}} \mathrm{Pb}_{(1-\mathrm{x})} \mathrm{I}_{3}$ perovskite solar cells covering up to $1060 \mathrm{~nm}$. J. Phys. Chem. Lett. 5, 1004-1011 (2014).

12. Stranks, S. D. et al. Electron-hole diffusion lengths exceeding 1 micrometer in an organometal trihalide perovskite absorber. Science 342, 341-345 (2013).

13. Han, Y. et al. Degradation observations of encapsulated planar $\mathrm{CH} 3 \mathrm{NH} 3 \mathrm{PbI} 3$ perovskite solar cells at high temperatures and humidity. J. Mater. Chem. A 3, 8139-8147 (2015).

14. Yang, J., Siempelkamp, B. D., Liu, D. \& Kelly, T. L. Investigation of CH3NH3PbI3 degradation rates and mechanisms in controlled humidity environments using in situ techniques. ACS Nano 9, 1955-1963 (2015).

15. Kedem, N. et al. Light-induced increase of electron diffusion length in a $\mathrm{p}-\mathrm{n}$ junction type $\mathrm{CH} 3 \mathrm{NH} 3 \mathrm{PbBr} 3$ perovskite solar cell. J. Phys. Chem. Lett. 6, 2469-2476 (2015).

16. Chen, Q. et al. Under the spotlight: The organic-inorganic hybrid halide perovskite for optoelectronic applications. Nano Today 10, 355-396 (2015).

17. Liu, Z. et al. Open-circuit voltages exceeding $1.26 \mathrm{~V}$ in planar methylammonium lead iodide perovskite solar cells. ACS Energy Lett. 4, 110-117 (2019).

18. Gholipour, S. et al. Globularity-Selected Large Molecules for a New Generation of Multication Perovskites. Adv. Mater. 29, 9. 1702005 (2017).

19. Noel, N. K. et al. Highly crystalline methylammonium lead tribromide perovskite films for efficient photovoltaic devices. ACS Energy Lett. 3, 1233-1240 (2018).

20. Aranda, C., Guerrero, A. \& Bisquert, J. Ionic effect enhances light emission and the photovoltage of methylammonium lead bromide perovskite solar cells by reduced surface recombination. ACS Energy Lett. 4, 741-746 (2019).

21. Wu, C.-G., Chiang, C.-H. \& Chang, S. H. A perovskite cell with a record-high-Voc of $161 \mathrm{~V}$ based on solvent annealed CH3NH3PbBr 3/ICBA active layer. Nanoscale 8, 4077-4085 (2016).

22. Sheng, R. et al. Methylammonium lead bromide perovskite-based solar cells by vapor-assisted deposition. J. Phys. Chem. C 119, 3545-3549 (2015).

23. Subhani, W. S. et al. Anti-solvent engineering for efficient semitransparent $\mathrm{CH} 3 \mathrm{NH} 3 \mathrm{PbBr} 3$ perovskite solar cells for greenhouse applications. J. Energy Chem. 34, 12-19 (2019).

24. Peng, J. et al. A universal double-side passivation for high open-circuit voltage in perovskite solar cells: role of carbonyl groups in poly (methyl methacrylate). Adv. Energy Mater. 8, 1-9 (2018).

25. Weng, B. et al. A layered $\mathrm{Na}_{1-\mathrm{x}} \mathrm{NiyFe}_{1-\mathrm{y}} \mathrm{O}_{2}$ double oxide oxygen evolution reaction electrocatalyst for highly efficient water-splitting. Energy Environ. Sci. 10, 121-128 (2017).

26. Shin, S. S. et al. Colloidally prepared La-doped BaSnO3 electrodes for efficient, photostable perovskite solar cells. Science 356, 167-171 (2017).

27. You, J. et al. Improved air stability of perovskite solar cells via solution-processed metal oxide transport layers. Nat. Nanotechnol. 11,75 (2015).

28. Correa-Baena, J.-P. et al. Identifying and suppressing interfacial recombination to achieve high open-circuit voltage in perovskite solar cells. Energy Environ. Sci. 10, 1207-1212 (2017).

29. Wang, F. et al. Highly efficient and stable perovskite solar cells by interfacial engineering using solution-processed polymer layer. J. Phys. Chem. C 121, 1562-1568 (2017).

30. Hamill, S., Cruz, T., Hagfeldt, A. \& Saliba, M. Demonstrating methylammonium-free, high-performance and stable perovskite solar cells on a planar, low-temperature architecture. Science 362, 449-453 (2018).

31. Zhao, P., Kim, B. J. \& Jung, H. S. Passivation in perovskite solar cells : A review. Materials Today Energy https://doi.org/10.1016/j. mtener.2018.01.004 (2018).

32. Sanchez, S. et al. Efficient and stable inorganic perovskite solar cells manufactured by pulsed flash infrared annealing. Adv. Energy Mater. 8, 1-9 (2018).

33. Sánchez, S., Jerónimo-Rendon, J., Saliba, M. \& Hagfeldt, A. Highly efficient and rapid manufactured perovskite solar cells via Flash InfraRed Annealing. Mater. Today https://doi.org/10.1016/j.mattod.2019.11.003 (2019).

34. Troughton, J. et al. Rapid processing of perovskite solar cells in under 25 seconds. J. Mater. Chem. A 3, 9123-9127 (2015).

35. Baker, J. et al. High throughput fabrication of mesoporous carbon perovskite solar cells. J. Mater. Chem. A 5, 18643-18650 (2017).

36. Martin, B. et al. Fabrication of flexible perovskite solar cells via rapid thermal annealing. Mater. Lett. 276, 128215 (2020).

37. Sánchez, S. et al. Flash infrared annealing as a cost-effective and low environmental impact processing method for planar perovskite solar cells. Mater. Today 31, 39-46 (2019).

38. Sanchez, S., Hua, X., Phung, N., Steiner, U. \& Abate, A. Flash infrared annealing for antisolvent-free highly efficient perovskite solar cells. Adv. Energy Mater. 8, 1-7 (2018).

39. Li, Y. et al. Multifunctional fullerene derivative for interface engineering in perovskite solar cells. J. Am. Chem. Soc. 137, 1554015547 (2015).

40. Kim, J., Ho-baillie, A. \& Huang, S. Review of novel passivation techniques for efficient and stable perovskite solar cells. Solar RRL 1800302, 1-16 (2019).

41. Saliba, M. et al. How to make over $20 \%$ Efficient perovskite solar cells in regular (n-i-p) and inverted (p-i-n) architectures. Chem. Mater. 30, 4193-4201 (2018).

\section{Author contributions}

M.S initiated the idea. P.F performed the experiments and wrote the manuscript. M.S and U.S supervised the research. All authors discussed the content, analyzed the data, reviewed and edited the manuscript.

\section{Funding}

Open Access funding enabled and organized by Projekt DEAL.

\section{Competing interests}

The authors declare no competing interests. 


\section{Additional information}

Supplementary Information The online version contains supplementary material available at https://doi. org/10.1038/s41598-020-79348-1.

Correspondence and requests for materials should be addressed to M.S.

Reprints and permissions information is available at www.nature.com/reprints.

Publisher's note Springer Nature remains neutral with regard to jurisdictional claims in published maps and institutional affiliations.

(c) (1) Open Access This article is licensed under a Creative Commons Attribution 4.0 International cc) License, which permits use, sharing, adaptation, distribution and reproduction in any medium or format, as long as you give appropriate credit to the original author(s) and the source, provide a link to the Creative Commons licence, and indicate if changes were made. The images or other third party material in this article are included in the article's Creative Commons licence, unless indicated otherwise in a credit line to the material. If material is not included in the article's Creative Commons licence and your intended use is not permitted by statutory regulation or exceeds the permitted use, you will need to obtain permission directly from the copyright holder. To view a copy of this licence, visit http://creativecommons.org/licenses/by/4.0/.

(C) The Author(s) 2020 